\title{
Narrative Analysis of the Impact of COVID-19 on Patients with Chronic Obstructive Pulmonary Disease, Their Caregivers, and Healthcare Professionals in Italy
}

\author{
Eleonora Volpato $\mathbb{1 D}^{1-3}$ \\ Stefano Centanni ${ }^{4}$ \\ Paolo Banfi (1) ${ }^{3}$ \\ Salvatore D'Antonio ${ }^{5}$ \\ Enrico Peterle ${ }^{6}$ \\ Filomena Bugliaro ${ }^{7}$ \\ Ignazio Grattagliano ${ }^{8}$ \\ Alessio Piraino (1D ${ }^{9}$ \\ Luca Cavalieri ${ }^{9}$ \\ Alfio Pennisi ${ }^{10}$ \\ Gianluca Danesi ${ }^{11}$ \\ Luigi Santoiemma ${ }^{12}$ \\ Maria Giulia Marini' \\ 'Healthcare Area, ISTUD Foundation, \\ Milan, Italy; ${ }^{2}$ Department of Psychology, \\ Università Cattolica del Sacro Cuore, \\ Milan, Italy; ${ }^{3}$ Heart-Respiratory \\ Rehabilitation Unit, IRCCS Fondazione \\ Don Carlo Gnocchi, Milan, Italy; \\ ${ }^{4}$ Department of Health Sciences \\ Università degli Studi di Milano - \\ Respiratory UnitASST Santi Paolo e \\ Carlo, Milan, Italy; ${ }^{5}$ Associazione ONLUS \\ BPCO, Rome, Italy; ${ }^{6}$ General \\ Practitioner, Local Health Department 3 \\ Serenissima, Venezia, Italy; ${ }^{7}$ Federasma \\ e Allergie-Federazione Italiana Pazienti \\ OdV, Prato, Italy; ${ }^{8}$ Italian College of \\ General Practitioners, Bari, Italy; ${ }^{9}$ Chiesi \\ Farmaceutici S.p.A, Parma, italy; \\ ${ }^{10}$ Rehabilitation Clinic Monsignor \\ Calaciura Biancavilla, Catania, Italy; \\ 'Local Health Department Romagna \\ Pulmonology Ravenna, Ravenna, Italy; \\ ${ }^{12}$ General Practitioner, Local Health \\ Department Bari, Bari, Italy
}

Correspondence: Eleonora Volpato

Email evolpato@istud.it
Purpose: The COVID-19 pandemic has disrupted many lives, including those of people suffering from chronic obstructive pulmonary disease (COPD) and their caregivers. The main aim of this study was to use narrative medicine, a validated approach promoting quality of care to explore how the COVID-19 pandemic impacted the quality of care, quality of life, psychological factors and social factors of people affected by COPD and their caregivers and healthcare professionals (HCPs). A secondary aim was to explore the role of telemedicine in combating isolation and providing access to care.

Methods: A cross-sectional observational narrative medicine study was conducted between July and November 2020 across Italy. An online semi-structured questionnaire with a narrative plot was completed by 146 participants (79 COPD patients, 24 caregivers, and 43 HCPs). Narrations were analyzed with descriptive statistics and evaluated using NVivo 11 software to break down the text and identify recurring themes and major semantic clusters. Results: During the first lockdown, $58.22 \%$ of responses from COPD patients indicated terror, fear and/or apprehension; at reopening, this figure was 35.44\%. Among caregivers, these figures were $100 \%$ at first lockdown and $45.83 \%$ at reopening. The metaphors most commonly used by patients to describe COPD and COVID-19 were monster and murderer, respectively. Patients described their homes more often as clean and lonely than as offering no shelter. The narratives of 42 COPD patients (45.2\%) described coping. Only $12.6 \%$ of COPD patients reported regular access to medical visits during lockdown, while $59.1 \%$ of general practitioners and pulmonologists reported using telemedicine, which was perceived as satisfactory by both patients and caregivers.

Conclusion: It is relevant to aim for a multidisciplinary and multilevel system of care that empowers telemedicine and integrates specific psychological support programs for COPD patients and their caregivers.

Keywords: chronic obstructive pulmonary disease, COPD, COVID-19, narrative medicine, quality of life

\section{Introduction}

The World Health Organization has predicted that, by 2030, chronic obstructive pulmonary disease (COPD) will be the fourth leading cause of death worldwide; it is estimated that about 8200 people worldwide die from COPD every day, and the life expectancy of patients seems to have diminished in recent years. In Italy, more than 1.6 million people ( $2.83 \%$ of the population) are affected by COPD. Although 
these data are worrying, COPD remains poorly understood by members of the general public, including many patients. $^{1}$

In contrast, many people have been affected by the three epidemics caused by the coronavirus family in the last two decades [Severe Acute Respiratory Syndrome2003 (SARS-2003), Middle East Respiratory Syndrome Coronavirus (MERS-Cov2012) and Severe Acute Respiratory Syndrome Coronavirus 2 (SARS-CoV -2-2019), which causes COronaVIrus Disease 19 (COVID-19)]. There is substantial genetic diversity among the pathogens responsible for these three epidemics, particularly between MERS and COVID-19. In the first two outbreaks, the primary disease hotspots were the Middle East, Saudi Arabia, and China, with very limited spreading to other countries., ${ }^{2,3}$ A recent report from the Center for Disease Control and Prevention suggests that more than one-third of adult patients who were hospitalized with COVID-19 had an airway-related condition such as COPD. ${ }^{4}$ The chronic nature of COPD, the severity of lung function impairment, and concomitant inflammation can compromise immune mechanisms and predispose patients to acute respiratory infections. In the absence of appropriate and timely treatment, and prior to the availability of vaccines, COVID-19 infection in COPD patients sometimes progressed to intolerable dyspnea, hypoxia, dry cough, and excessive fatigue with or without sputum production. Some patients developed pneumonia which led to hospitalization, ICU admission, and sometimes death. Starting on February 21, 2020, when the first Italian cases were reported, and progressing through March 11, by which time COVID-19 had expanded throughout all of Italy, Italians suddenly found themselves under curfew for the first time since the Second World War. They could not go out except to engage in classroom teaching, to meet healthcare needs, and to purchase food. Later, schools were closed and distance learning was implemented; weddings and funerals were prevented; bars, restaurants, stores, gyms, swimming pools, cinemas, theaters, museums, discos, and ski resorts were closed; sporting events were cancelled; and driving exams were suspended. Those who did not have to be physically present at their workplaces began to work from home. While these dramatic changes to daily life affected everyone, COPD patients were predicted to be more susceptible than most people to consequent psychological symptoms and disorders such as post-traumatic stress disorder, fear, anxiety, depression, and suicidal ideation. Even under normal circumstances, approximately $40 \%$ of patients with COPD exhibit clinically relevant depressive symptoms (eg excessive fatigue and loss of interest in pleasurable activities), while $36 \%$ exhibit anxiety symptoms (eg nervousness, fear, and panic) that may warrant medical intervention. ${ }^{5}$ COPD patients with comorbid anxiety and depression may exhibit worsening symptoms, culminating in fear of self-isolation, excessive worry, loss of social support, and physical distancing (on top of the social distancing measures implemented due to the pandemic). ${ }^{6}$ Increased unemployment and other financial stressors, along with the "bad news" delivered daily via social media, discouraged and demoralized many, especially among older COPD patients. ${ }^{7}$ Owing to social isolation and limited communication, few data are available regarding the emotions that COPD patients are experiencing and the strategies they are implementing to cope with this disruptive event, which may include adverse social behaviors such as active smoking, which is a risk factor for worsening lung condition, excessive drinking or substance abuse, to a disproportionate extent relative to patients with other chronic diseases. Therefore, it is relevant to explore the experiences of COPD patients, their relatives and other caregivers, and the professionals treating them to facilitate the development of interventions that can alleviate postCOVID-19 impact on physical activities, cognitive function, and mental health in patients with COPD. This involves listening to patients' stories, taking time to recognize their emotions and thoughts, and then transcribing these into a permanent record that will become part of the care pathway. Narrative medicine (NM) sheds light on patients' and caregivers' experiences, with particular focus on their beliefs, emotions, needs, thoughts, and plans, and on their relationship with healthcare professionals (HCPs). ${ }^{8,9}$ The narratives of HCPs treating COPD patients are also important as a key to understanding the quality of pathways of care. ${ }^{10}$

\section{Aims}

The main objective was to explore how the COVID-19 pandemic impacted the quality of care, quality of life, psychological and social factors in people with COPD, their relatives and other caregivers, and their HCPs. A secondary aim was to explore how telemedicine in the digital/COVID-19 era is described by HCPs and patients and whether it should continue to be included in patient care. 


\section{Methods}

\section{Theoretical Framework}

According to Charon ${ }^{11}$ and the Guidelines for the Application of Narrative Medicine in Clinical Practice developed by the Istituto Superiore di Sanità (Italian Health Institute) as part of the Consensus Conference in $2014,{ }^{12} \mathrm{NM}$ refers to a methodology of clinical intervention based on a specific communicative competence. The narrative is the fundamental tool by which NM practitioners acquire, understand and integrate the various points of view of those involved in a disease and its care process. The goal is the shared construction of a personalized care pathway (care story). NM integrates with evidence-based medicine and, by offering a plurality of perspectives, makes clinical care decisions more complete, personalized, effective, and appropriate.

\section{Research Design and Setting}

A cross-sectional observational NM study was conducted between July and November 2020 at seven hospitals, five outpatient clinics operated by general practitioners (GPs), and two patients' associations for pulmonary diseases across Italy. Beginning in July 2020, GPs, pulmonologists, and HCPs working at these inpatient and outpatient clinics and associations took part in a voluntary training session about NM and the aims and methods of this project.

Subsequently, each of these practitioners invited their COPD patients and those patients' caregivers to participate and provided an information sheet containing the link to the survey and all other details on how to participate in this project. Social networking was also used to broaden the sample of patients, caretakers and professionals to make it as heterogeneous as possible in terms of geographical location within Italy, ensuring the generalization of data.

The online survey was available from the Fondazione ISTUD web portal, https://www.medicinanarrativa.eu/nar rarsi-covid-19, in a section dedicated to facilitating narrative collection. Participants were asked to fill in the online illness plot, ${ }^{13}$ download it to a personal computer, save it, and either email the completed survey or print it and mail it to Fondazione ISTUD. Alternatively, it was possible to respond by telephone interview with the researchers, especially for those participants who were isolated or otherwise without help and who were not comfortable with electronic communication. In cases where interviews were conducted by telephone, these interviews were audio-recorded with the participant's consent and transcribed verbatim to ensure data reliability.

\section{Participant Selection}

A convenience sample was recruited from all of the abovementioned inpatient and outpatient clinics and associations using the following inclusion criteria: patients with COPD of any severity according to the GOLD criteria ${ }^{14}$ or caregivers for patients with this chronic respiratory disease, aged $\geq 18$ years old with no cognitive impairment documented prior to recruitment, or HCPs (preferably pulmonologists or GPs) treating patients with COPD. Participant recruitment continued until saturation was achieved.

\section{Data Collection}

A semi-structured questionnaire was submitted to each participant, followed by a narrative plot (Supplementary data 1) that guided each participant in creating a narrative that traced the journey between illness and care during the COVID-19 health emergency, with attention to the emotional, social, and relational dimensions of the events. Through this research, we came to better understand what behaviors may be effective in promoting resilience, adaptation, discipline, and creativity under the current conditions of social isolation. Specifically, the quantitative-qualitative questionnaires focused on the collection of sociodemographic data; risk factors and treatments; emotions during lockdown; treatments during the COVID-19 pandemic; questions related to COVID-19; COPD management during the COVID-19 emergency (daily activities and access to care and services both inperson and via telemedicine); and narratives about daily living. The time required to complete the questionnaire and the narrative plot was approximately 45 minutes. After data collection, early results were shared with participating centers and associations through a webinar, for an alignment on data interpretation.

\section{Ethical Considerations}

Persons diagnosed with COPD, caregivers, and HCPs shared their narratives anonymously. Furthermore, the researchers were not able to identify any potential relationship between participants. Before writing their narratives, participants provided online written informed consent after being informed on the project's aims and confidential data handling procedures, according to Italian Law 196/2003 on Privacy and Safeguarding of Sensitive Data and the GDPR of the European Union 2016/679. The project was approved 
by the "IRCCS Fondazione Don Carlo Gnocchi, Milan, Italy" del Comitato Etico IRCCS Regione Lombardia (09/ 12/2020). The project was conducted in accordance with the Declaration of Helsinki and the participant consent included publication of anonymized responses.

\section{Data and Narrative Analysis}

Sociodemographic variables were analyzed with descriptive statistics (means, ranges, standard deviations), and frequencies were reported as percentages, using Jamovi 1.6.16 software ${ }^{\circledR}$. This analysis helped us understand the characteristics of the respondents and better contextualize the qualitative responses.

The narrative plots, written in the local language (Italian), were read independently by two Fondazione ISTUD researchers (EV; MGM), who attempted to understand the dominant and distinctive features of each text. The narratives were evaluated both in aggregate form, breaking down the collection of texts to identify recurring themes and major semantic clusters using the dedicated software program NVivo11 (QSR International ${ }^{\circledR}$, Melbourne, Australia), and separately to respect their qualitative value. In particular, for the purposes of qualitative analysis, peculiar attention was paid to:

-identification of recurring themes;

-language analysis for recurring expressions, words, verbal modes and tenses, metaphors, punctuation, and underlining;

-semantic analysis;

-emotional analysis according to Plutchik's wheel of emotions; ${ }^{15}$

-thematic analysis, based on two classifications used in the field of NM:

- the classification proposed by Kleinman, ${ }^{16}$ ie the analysis of a lexical distinction in the English language that places great semantic significance on "being ill": i) Disease-centered: a precise and punctilious description of the disease through technical language (as on a medical chart), which leaves no room for personal considerations about one's state of mind. These reveal an underlying embarrassment, a lack of habit of telling one's story, or a lack of acceptance of one's condition, as indicated by the strict exclusion of emotions from the medical narrative; ii) Illness-centered: a narrative that places the experience of being ill at the center, including accounts of emotions, mental suffering, the search for the psychological causes of the disease in one's memories of childhood or adolescence, and descriptions of social relationships and the illness's impact on the patient's relational life, family, and work. These narratives reveal a desire to tell one's stories and an acceptance of one's physical condition, as required for a deeper inner search. Emotions are acknowledged but governed; and iii) Sickness-centered : a narrative focused on society's perception of the illness and the sick person. The disease is interpreted through the narration of the same, a narration that, for Kleinman, hinges around four conceptual cores (the discovery and recognition of symptoms, the culturally mediated idea of the disease, its personal and interpersonal meaning, and the interpretative models of the patient and his family), the analysis of which allows researchers to identify the plot and the rhetorical mechanisms that-as in any story-are the basis for the construction of the plot.

- the classification proposed by Launer, ${ }^{17}$ Associate Dean for Faculty Development for Health Education England, which stresses how patients tell us about their illnesses because they know it will help clinicians make a diagnosis and offer treatment, but also because they expect clinicians as fellow human beings to be interested in their experiences: (i) Steady or stable stories (traversing the journey from past to present); ii) Regressing stories (mainly focused on the past, with few detours into the present and none to the future), which tend to be told in the absence of coping strategies; and iii) Evolving or progressive stories (which range between past, present, and future), which tend to be told when coping is activated.

Coping is defined as the conscious effort to solve personal and interpersonal problems by attempting to overcome, minimize, or tolerate stressful or conflicting situations. ${ }^{18,19}$

Results are presented in terms of five main topics: (a) Quality of care (COPD management and telemedicine, and protections and care during the lockdown); (b) Quality of life (COPD experience during the pandemic, analyzed through NM classifications and metaphors and the experience of writing); (c) Psychological factors (ie emotions); (d) Social factors (ie support, home, and work); and (e) Coping strategies emerging from the narratives.

\section{Results}

\section{Sociodemographic Characteristics}

One hundred and eighty-six persons accessed the platform. In the end, 83 COPD patients, 25 caregivers and 47 HCPs 
took part in the project. Both the online semi-structured questionnaire and the narrative plot were completed by 146 participants (79 COPD patients, 24 caregivers, and 43 HCPs) (Figure 1). Anyone who completed either the online semi-structured questionnaire or the narrative plot or both was included in the analysis, for a total of 83 COPD participants, 25 caregivers, and 47 HCPs. $50.7 \%$ of COPD patients said that they were insufficiently confident with new technologies or did not have a computer or smartphone and accordingly opted for the telephone interview. It is noteworthy that it was mostly elderly people, with an average age of 71.1, who told their stories in this study.

Table 1 summarizes participants' sociodemographic data and includes non-responses as a separate category. While there was substantial parity of involvement for men and women among participants with COPD and HCPs, there was a larger proportion of women among the caregivers [16 (61.5\%) women, 9 (34.6\%) men]. Moreover, the participating HCPs were younger than those who took part in other surveys (mean age 37.2 years, $\mathrm{SD}=10.2$, range 22-61).

Quotes from narratives are presented in the figures and tables, where applied codes differ from those used to identify participants to reduce the risk of re-identification.

\section{Quality of Care}

COPD Management and Telemedicine During the First Lockdown

\section{Daily Habits}

Regarding physical activity during the lockdown period, the most common response from COPD patients indicated no exercise $(35,43.8 \%)$; this was followed by $19(22.9 \%)$ people who refrained from answering, $13(16.3 \%)$ who exercised less than usual, nine (11.3\%) who exercised as much as usual, and seven (8.7\%) who exercised more than usual.

Regarding smoking habits, 19 (22.9\%) were smokers at the time of the survey, 53 (63.9\%) were former smokers, and $11(11.3 \%)$ had never smoked. Most of those who had stopped smoking did not quit following their diagnosis with COPD (34, 64.2\%), while 19 (35.8\%) did quit following their diagnosis. Of those who had quit smoking, two $(3.9 \%)$ had quit just a few days before the interview.

\section{Medication Therapy}

Among the participants with COPD, 41 (52.8\%) were on oxygen therapy, while $28(35.9 \%)$ were not and 10 $(12.6 \%)$ did not answer this question. Sixty (75.9\%) people used bronchodilators, while six (7.6\%) did not and 13

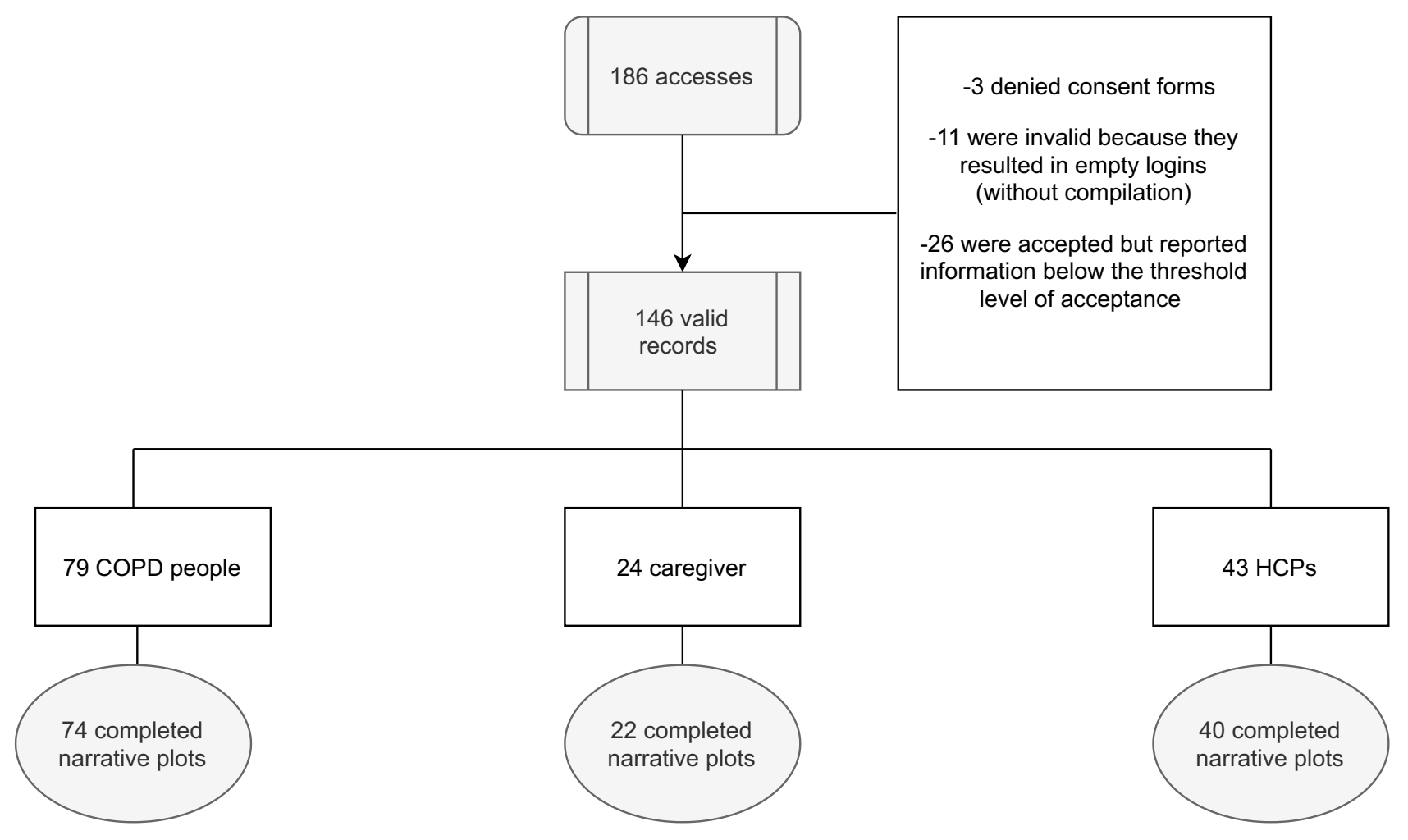

Figure I Flow chart of participant selection. 
Table I Sociodemographic Data

\begin{tabular}{|c|c|c|c|}
\hline & $\begin{array}{l}\text { Patients } \\
(\mathrm{N}=83)\end{array}$ & $\begin{array}{c}\text { Caregivers } \\
(\mathrm{N}=\mathbf{2 5})\end{array}$ & HCPs $(N=47)$ \\
\hline \multicolumn{4}{|l|}{ Gender } \\
\hline Women & $42(50.6 \%)$ & $16(61.5 \%)$ & $23(48.9 \%)$ \\
\hline Men & 41 (49.4\%) & $9(34.6 \%)$ & $24(51.1 \%)$ \\
\hline Not declared & $0(0 \%)$ & $0(0 \%)$ & $0(0 \%)$ \\
\hline \multicolumn{4}{|l|}{ Average age (yrs) } \\
\hline Mean (SD) & $68.8(13.9)$ & $51(16)$ & $37.2(10.2)$ \\
\hline \multicolumn{4}{|l|}{ Geographic residence } \\
\hline Northern Italy & $34(43.6 \%)$ & $13(56.5 \%)$ & $7(16.3 \%)$ \\
\hline Central Italy & 6 (7.7\%) & $2(8.69 \%)$ & $3(7 \%)$ \\
\hline Southern Italy & $38(48.7 \%)$ & $8(34.8 \%)$ & $33(76.7 \%)$ \\
\hline Nonresponses & 5 (6.02\%) & $2(8 \%)$ & $4(8.5 \%)$ \\
\hline \multicolumn{4}{|l|}{ Settlement size } \\
\hline$<10.000$ inhabitants & $27(32.5 \%)$ & - & $6(12.8 \%)$ \\
\hline $10.000-25.000$ inhabitants & $21(25.3 \%)$ & - & $25(53.2 \%)$ \\
\hline $25.000-50.000$ inhabitants & 8 (9.6\%) & - & $8(17 \%)$ \\
\hline $50.000-250.000$ inhabitants & 7 (8.4\%) & - & $3(6.4 \%)$ \\
\hline$>250.000$ inhabitants & 19 (22.9\%) & - & $5(10.6 \%)$ \\
\hline Nonresponses & I (I.2\%) & - & - \\
\hline \multicolumn{4}{|l|}{ Education } \\
\hline Elementary school & $23(27.9 \%)$ & $\mathrm{I}(3.8 \%)$ & - \\
\hline Middle school & $9(10.8 \%)$ & 5 (19.2\%) & - \\
\hline High school & $33(39.8 \%)$ & $12(46.2 \%)$ & - \\
\hline Bachelor/Master/PhD & 17 (20.5\%) & $7(26.9 \%)$ & - \\
\hline Nonresponses & I (I.2\%) & $0(0 \%)$ & - \\
\hline \multicolumn{4}{|l|}{ Employment status } \\
\hline Employee & $9(10.8 \%)$ & $8(30.8 \%)$ & - \\
\hline Housewares & $11(13.3 \%)$ & $3(11.5 \%)$ & - \\
\hline Not working due to COPD & $3(3.6 \%)$ & - & - \\
\hline Not working due to other diseases/reasons & $4(4.8 \%)$ & - & - \\
\hline Retired & $48(57.8 \%)$ & $2(7.7 \%)$ & - \\
\hline Unable to work & $\mathrm{I}(1.2 \%)$ & - & - \\
\hline Freelancers & 7 (8.43\%) & $8(30.8 \%)$ & - \\
\hline Nonresponses & - & $4(16 \%)$ & - \\
\hline \multicolumn{4}{|l|}{ Marital state } \\
\hline Single & $5(6 \%)$ & $8(30.8 \%)$ & - \\
\hline Married & $42(50.6 \%)$ & - & - \\
\hline Separated/Divorced & $16(19.3 \%)$ & $12(46.2 \%)$ & - \\
\hline Widowers & $19(22.9 \%)$ & $4(15.4 \%)$ & - \\
\hline Cohabitant & - & $\mathrm{I}(3.8 \%)$ & - \\
\hline Nonresponses & I (I.2\%) & - & - \\
\hline \multicolumn{4}{|l|}{ Role } \\
\hline Daughter or son & - & 15 (57.7\%) & - \\
\hline Spouses/partners & - & $6(23.1 \%)$ & \\
\hline Parents & - & $2(7.7 \%)$ & - \\
\hline Sister or brother & - & I (3.8\%) & - \\
\hline Friend & - & I (3.8\%) & - \\
\hline Nonresponses & - & - & \\
\hline
\end{tabular}

(Continued) 
Table I (Continued).

\begin{tabular}{|c|c|c|c|}
\hline & $\begin{array}{l}\text { Patients } \\
(\mathrm{N}=83)\end{array}$ & $\begin{array}{c}\text { Caregivers } \\
(\mathrm{N}=25)\end{array}$ & HCPs $(N=47)$ \\
\hline \multicolumn{4}{|l|}{ Smoking } \\
\hline Smokers & $19(22.9 \%)$ & 8 (30.8\%) & - \\
\hline Ex-smokers & $53(63.9 \%)$ & $4(15.4 \%)$ & - \\
\hline Non-smokers & II (II.3\%) & $13(50 \%)$ & - \\
\hline Nonresponses & - & - & \\
\hline \multicolumn{4}{|l|}{ COPD severity } \\
\hline Very severe & $5(6 \%)$ & $3(11.5 \%)$ & - \\
\hline Severe & $28(33.7 \%)$ & $8(30.8 \%)$ & - \\
\hline Moderate & $35(42.2 \%)$ & $10(38.5 \%)$ & - \\
\hline Mild & $12(14.5 \%)$ & $3(11.5 \%)$ & - \\
\hline Nonresponses & $3(3.61 \%)$ & I (4\%) & - \\
\hline \multicolumn{4}{|l|}{ Specialisation } \\
\hline Pulmonologist & - & - & $5(11.4 \%)$ \\
\hline General Practitioner & - & - & $4(9.1 \%)$ \\
\hline Geriatrician & - & - & $2(4.5 \%)$ \\
\hline Other specialisations & - & - & $12(25.53 \%)$ \\
\hline Physiotherapist & - & - & $10(22.7 \%)$ \\
\hline Homeopath & - & - & $2(4.5 \%)$ \\
\hline Nurse & - & - & $6(12.8 \%)$ \\
\hline Healthcare worker & - & - & $6(12.8 \%)$ \\
\hline \multicolumn{4}{|l|}{ Workplace } \\
\hline Hospital & - & - & $5(10.6 \%)$ \\
\hline University Hospital & - & - & I (2.1\%) \\
\hline Local Health Authority & - & - & $34(72.3 \%)$ \\
\hline Private practice & - & - & $4(8.5 \%)$ \\
\hline Rehabilitation Centre & - & - & $2(4.3 \%)$ \\
\hline Nonresponses & - & - & I (2.1\%) \\
\hline
\end{tabular}

Note: Data presented as N (\%).

Abbreviations: SD, standard deviation; mean, minimum-maximum.

(16.5\%) did not answer this question. Inhaled corticosteroids were used by 56 (70.9\%) people, while 11 (13.9\%) people did not use them and $12(15.2 \%)$ did not answer this question. Systemic corticosteroids were taken by 36 (45.6\%) people, while 27 (34.2\%) did not take them and $16(20.3 \%)$ did not respond. Antibiotics were taken by 15 (19\%) people, while most did not take them $(47,59.5 \%)$ or did not respond (17, 21.5\%).

Only a small minority $(6 \%-7 \%)$ of patients expressed the opinion that inhalation therapy performed twice daily (morning and evening) could hinder the management of respiratory disease and diminish quality of life. This opinion was slightly more common among healthcare workers (7\%-12\%) and much more common among caregivers (42\%). Most patients, caregivers, and HCPs believed that inhalation therapy performed twice daily (morning and evening) could guarantee greater $24 \mathrm{~h}$ therapeutic coverage. The opinion that twice daily (morning and evening) inhalation therapy had little or no impact on treatment efficacy over 24 hours was expressed by $5 \%, 20 \%$, and $7 \%$ of patients, caregivers, and HCPs, respectively.

\section{Telemedicine}

Seven patients with COPD $(9 \%)$ received communications from their GP during the first lockdown, whereas 29 (37\%) did not receive them, 25 (31\%) did not need them, and 18 (22.8\%) did not respond to this question. In contrast, 34 $(43 \%)$ received communications from their pulmonologist, while $18(23 \%)$ did not receive them, 11 (14\%) did not need them, and 16 (20.2\%) did not respond to this question. During the lockdown period, 19 (24\%) received care via telemedicine from their GP, while 38 (48\%) received care via telemedicine from their pulmonologist. Two persons $(2 \%)$ received home visits from their GP and $9(11 \%)$ 
had access to outpatient visits, compared to 32 (41\%) who were seen in the hospital by a pulmonologist as needed. Regarding access to COPD-related specialist visits, five (20\%) people were currently on a waiting list for a specialist visit, while $8(32 \%)$ were not and $12(48 \%)$ did not respond to this question.

Fourteen (58.3\%) caregivers reported that the GP did not send communications to their family members during the lockdown, while $11(46 \%)$ caregivers reported that the pulmonologist did not send communications. However, 10 (41.6\%) caregivers stated that the GP assisted their family member via telemedicine when needed, and $12(50 \%)$ stated that the pulmonologist did. Sixteen (66.6\%) caregivers confirmed that there were no home visits, while 12 $(50 \%)$ confirmed that there were no clinic visits. Nine $(37.5 \%)$ caregivers said that their family members had hospital visits with a pulmonologist.

Thirty-five (81.4\%) HCPs stated that they were able to continue caring for people with COPD, whereas four $(9.3 \%)$ responded that they were unable to do so and five $(11.6 \%)$ did not respond to this question. Twenty-three (53.5\%) HCPs had no concerns about whether one of their COPD patients would be hospitalized during the lockdown, whereas $15(34.9 \%)$ did and five (11.6\%) refrained from answering. Many of the GPs and pulmonologists $(59.1 \%)$ reported having practiced telemedicine, which was considered satisfactory by the patients who received it and their caregivers. Twenty-six (60.5\%) HCPs assisted people with COPD remotely when needed. Seventeen (39.5\%) visited at least one person with COPD at home when needed. In other cases, visits were made in the outpatient clinic $(22,51.2 \%)$ or the hospital $(23,53.5 \%)$.

\section{Hospitalizations}

Fifty-three $(64.6 \%)$ participating patients had been hospitalized for COPD in the past two years, while $22(26.8 \%)$ had not been and seven (8.5\%) did not answer this question. The mean number of days of hospitalization in the past two years was 26.4 ( $\mathrm{SD}=12.5$, range $0-60$ ).

Five $(6 \%)$ COPD patients tested positive for COVID19 on a swab test, whereas six (7.2\%) tested negative, 66 (79.5\%) did not take a test, and six (7.2\%) did not respond. Four COPD patients were admitted to a Department of Pneumology or Intensive Care for COVID-19. One person specified that he/she was hospitalized for 90 days, while another was hospitalized for only a couple of weeks, but remained positive for another month following discharge. In $4 \%$ of cases, the caregivers also became ill.

\section{Protections and Care During the Lockdown}

Forty-nine COPD patients $(60.5 \%)$ stated that they had followed the rules of social distancing very scrupulously during the lockdown period, while 14 (17.3\%) reported having followed them fairly scrupulously, 15 (18.5\%) refrained from answering, and the others had followed them little $(2,2.5 \%)$ or not at all $(1,1.2 \%)$. Similarly, most caregivers said that they had followed the social distancing rules very scrupulously $(14,53.8 \%)$, followed by seven $(26.9 \%)$ who had followed them fairly scrupulously, and $2(7.7 \%)$ who had not followed them very scrupulously. Two people (7.7\%) abstained from answering.

Fifty-two (64.2\%) COPD patients affirmed that they had received help obtaining medicines and/or other necessities, while $21(25.9 \%)$ had not and eight (9.9\%) did not respond to this question. Most participants had had no difficulty obtaining medications for their condition (61, $75.3 \%)$, while nine $(11.1 \%$ ) had had some trouble and 11 $(13.6 \%)$ did not answer this question. Fifty-two people said that they followed their therapy regimens just as closely as they had prior to lockdown $(52,65 \%)$, while $21(26.3 \%)$ people followed them more closely during lockdown than they had prior to lockdown. Five $(6.3 \%)$ people did not answer this question and two (2.5\%) said that they followed them less diligently during lockdown.

Both patients and caregivers complained about the difficulty of obtaining sufficient quantities of PPE, specifically, masks and gloves, especially during the first lockdown phase.

\section{Quality of Life}

COPD Experience During the Pandemic Analyzed Through NM Classifications and Metaphors

The narrations were typically very brief and telegraphic but intense. Some participants appeared to have difficulty verbalizing their own experiences, while other participants seemed to try only half-heartedly to tell their stories.

\section{Classification by Launer}

As grouped according to Launer's classification, most of the 56 narratives of COPD patients (90 expressions) were identifiable as stable stories beginning in the past and proceeding to the present $(48,53.3 \%$; 24 COPD patients) (Figure 2). The most commonly used verb in these stable 


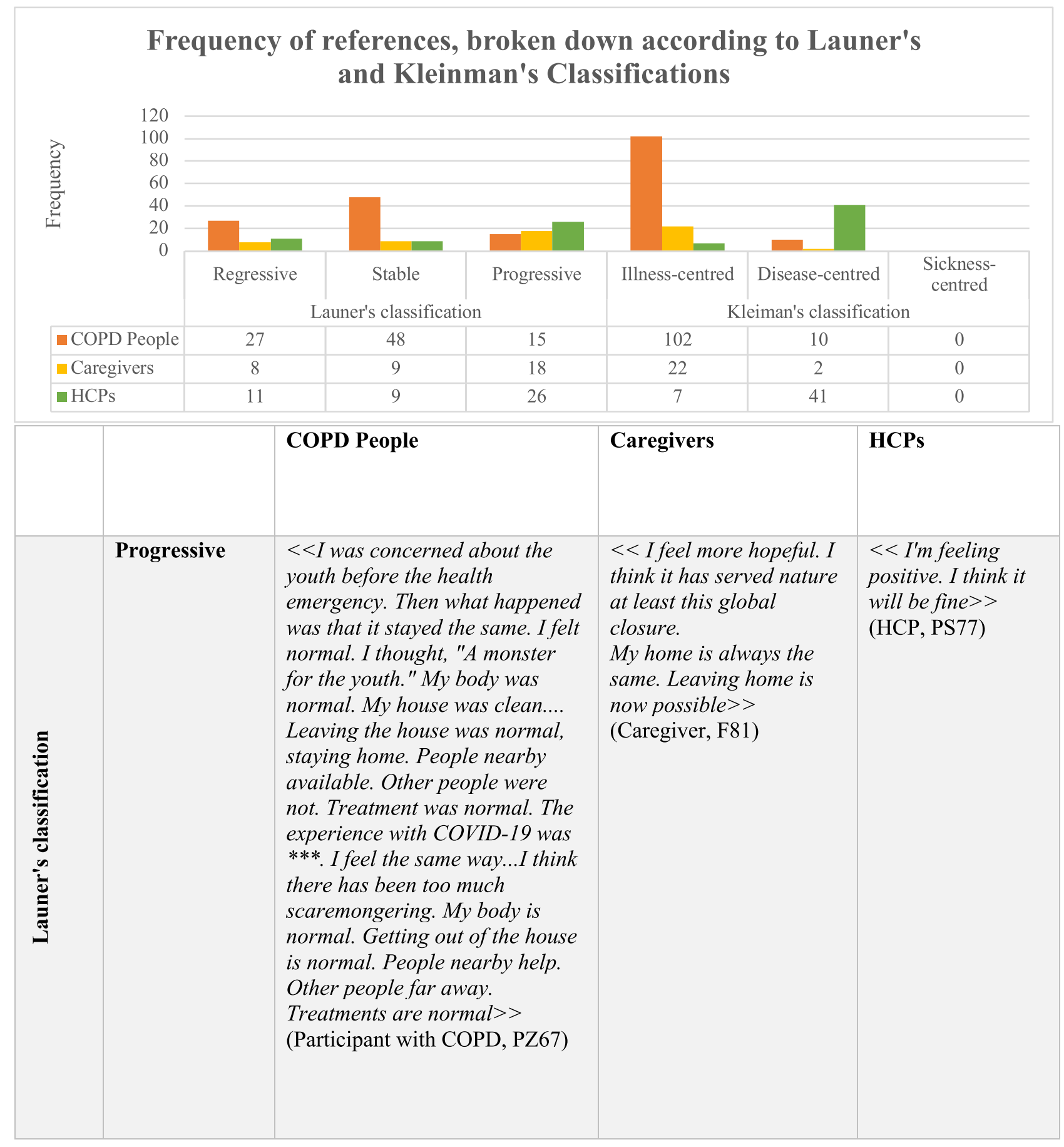

Figure 2 Continue. 


\begin{tabular}{|c|c|c|c|c|}
\hline & Stable & $\begin{array}{l}<<\text { I was very calm before the } \\
\text { health emergency, despite my } \\
\text { illness. Then it happened that the } \\
\text { anxiety of not to catch the virus } \\
\text { every day immobilized me. I felt } \\
\text { oppressed. I thought I was in } \\
\text { danger. My body was anxious. } \\
\text { My house was all too neat. } \\
\text { Leaving the house was for } \\
\text { emergencies. People nearby } \\
\text { were actually far away. Other } \\
\text { people non-existent. Work was } \\
\text { impossible. Care was present. } \\
\text { The experience with COVID-19 } \\
\text { was traumatic. I feel strange. I } \\
\text { think it can happen again. My } \\
\text { body is gripped with fear. } \\
\text { Getting out of the house is } \\
\text { possible. Nearby people keep } \\
\text { calling, while other people non- } \\
\text { existent. Working is difficult, but } \\
\text { now possible...> (Participant } \\
\text { with COPD, PZ88) }\end{array}$ & $\begin{array}{l}<<\text { I feel on alert. I think } \\
\text { everything can close up } \\
\text { again. My home is cold } \\
\text { and full of fear. Leaving } \\
\text { the house is possible and } \\
\text { at the same time } \\
\text { dangerous }>>\text { (Caregiver, } \\
\text { F45) }\end{array}$ & $\begin{array}{l}\quad<<\text { For tomorrow } \\
\text { I imagine that } \\
\text { things don't } \\
\text { change. And I'd like } \\
\text { for the first time to } \\
\text { put health first. } \\
\text { place }>>\text { (HCP, } \\
\text { PS66) }\end{array}$ \\
\hline & Regressive & $\begin{array}{l}<<\text { From February to August I } \\
\text { have remained at home. for the } \\
\text { shopping and various I have } \\
\text { found suppliers that carried to } \\
\text { house, what I asked. With a not } \\
\text { indifferent cost of tips. Being } \\
\text { also my wife a 70-year-old } \\
\text { COPD. I found a lot of } \\
\text { availability at my pulmonologist, } \\
\text { who continued to follow us by } \\
\text { phone. Getting out of the house } \\
\text { was tiring, even with the } \\
\text { prolapse. Gone are the days of } \\
\text { projects }>>\text { (Participant with } \\
\text { COPD, PZ23) }\end{array}$ & $\begin{array}{l}<<\text { Then what happened } \\
\text { was that chaos took over. } \\
\text { I felt in danger for him. I } \\
\text { thought he was going to } \\
\text { die...The house was } \\
\text { messy }>>\text { (Caregiver, } \\
\text { F44) }\end{array}$ & $\begin{array}{l}<<\text { For tomorrow I } \\
\text { can't imagine a } \\
\text { tomorrow }>> \\
(\mathrm{HCP}, \mathrm{PS} 55)\end{array}$ \\
\hline 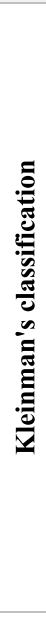 & Illness-centred & $\begin{array}{l}<<\ldots \text { my body was } \\
\text { motionless... >> (Participant with } \\
\text { COPD, PZ71) }\end{array}$ & $\begin{array}{l}<<\ldots \text {.. it was very hard } \\
\text { because in spite of } \\
\text { everything we didn't } \\
\text { know, my husband didn't } \\
\text { eat, didn't sleep, he was } \\
\text { agitated and scared and } \\
\text { also, I lived his life in } \\
\text { symbiosis with him. We } \\
\text { were very afraid, my } \\
\text { husband suffered from } \\
\text { panic attacks, we thought } \\
\text { he was sick, but it was } \\
\text { just anxiety, so I started } \\
\text { to give him a tranquilizer } \\
\text { so he is calm and lives life } \\
\text { without fear, but the } \\
\text { panic was strong in the } \\
\text { first period because we } \\
\text { always heard on the news }\end{array}$ & $\begin{array}{l}<<\text { Ifelt agitated } \\
\text { stressed sad. I } \\
\text { thought about } \\
\text { getting sick. My } \\
\text { days were the } \\
\text { same }>>\text { (HCP, } \\
\text { PS89) }\end{array}$ \\
\hline
\end{tabular}

Figure 2 Continue. 


\begin{tabular}{|c|c|c|c|}
\hline & & $\begin{array}{l}\text { dead, dead, dead ... they } \\
\text { told us every day how } \\
\text { many dead, how many } \\
\text { infected, how many } \\
\text { hospitalized }>> \\
\text { (Caregiver, F34) }\end{array}$ & \\
\hline $\begin{array}{l}\text { Disease- } \\
\text { centred }\end{array}$ & $\begin{array}{l}<<\text { Nothing works, we are } \\
\text { supported by nothing. if nothing } \\
\text { else last year worked } \\
\text { vaccinations this year not even } \\
\text { that the health system has } \\
\text { collapsed in my opinion. I don't } \\
\text { even believe in the swab because } \\
\text { it can give false results because } \\
\text { you can have a negative result } \\
\text { and be positive, and then it } \\
\text { leaves time to find, because } \\
\text { maybe after } 10 \text { days or a week I } \\
\text { am negative...>> (Participant } \\
\text { with COPD, PZ78) }\end{array}$ & $\begin{array}{l}<<\text { The care of my family } \\
\text { member with COPD } \\
\text { fortunately did not } \\
\text { undergo any changes } \\
\text { from the therapeutic } \\
\text { routine: he has always } \\
\text { provided independently, } \\
\text { with supervision from me. } \\
\text { My family member has } \\
\text { understood the } \\
\text { importance of observing } \\
\text { sanitary rules during } \\
\text { lockdown (hand washing, } \\
\text { social distancing, masks } \\
\text { and gloves, where } \\
\text { available) all the more so } \\
\text { given his respiratory } \\
\text { problems; since the } \\
\text { diagnosis of COPD, } \\
\text { followed by a period of } \\
\text { respiratory FKT, he has } \\
\text { learned to use the } \\
\text { saturating meter I } \\
\text { provided. On the positive } \\
\text { side, there has been a } \\
\text { greater adherence on his } \\
\text { part to night-time oxygen } \\
\text { therapy>> (Caregiver, } \\
\text { F56) }\end{array}$ & $\begin{array}{l}<<\text { Before the } \\
\text { health emergency, } \\
\text { my profession as a } \\
\text { general } \\
\text { practitioner was } \\
\text { carried out for half } \\
\text { the day in the } \\
\text { outpatient clinic } \\
\text { and for the other } \\
\text { half at the home of } \\
\text { the patients (visits } \\
\text { to chronic patients } \\
\text { and visits requested } \\
\text { for various reasons } \\
\text { by patients who } \\
\text { could not go to the } \\
\text { clinic). Part of the } \\
\text { work done in the } \\
\text { outpatient clinic } \\
\text { was also of a } \\
\text { bureaucratic } \\
\text { nature } \\
\text { (prescriptions, } \\
\text { answers to e-mails, } \\
\text { prescriptions of } \\
\text { various aids and } \\
\text { devices, filling out } \\
\text { disability } \\
\text { applications, etc.). } \\
\text { My work, although } \\
\text { sometimes } \\
\text { burdened by } \\
\text { unforeseen events, } \\
\text { was still quite } \\
\text { serene and always } \\
\text { rewarded by a } \\
\text { good relationship } \\
\text { with my patients >> } \\
\text { (HCP, PS87) }\end{array}$ \\
\hline $\begin{array}{l}\text { Sickness- } \\
\text { centred }\end{array}$ & None & None & None \\
\hline
\end{tabular}

Figure 2 Frequency of expressions broken down according to Launer's and Kleinman's classifications. 
stories was "were" $(15,16.7 \%)$, referring mainly to factual elements and related to a sense of reality. Care is commonly described as "present" $(10 ; 11.1 \%)$. Many expressions describing the "body" $(5 ; 5.5 \%)$ depict it as "motionless" (3; 3.3\%). 27 expressions (30\%; 19 COPD patients) contained hallmarks of regressing stories, while 15 contained hallmarks of evolving stories $(16.6 \% ; 13$ COPD participants). In the regressing stories, one of the most used verbs was "get out" $(7,7.8 \%)$, often accompanied by "forbid" or "prevent" $(3,3.3 \%)$. The verb "to die" $(3,3.3 \%)$, commonly related to "thinking" and "distress" $(3,3.3 \%)$, was also used. In the stories in progression, in contrast, the most frequently used word was "hope" or the verb "I hope" $(5,5.6 \%)$ and the terms "tranquility" and "vaccine" (2, 2.2\%) (Figure 2).

There were 35 expressions in the narrative plots of 25 caregivers that could be classified according to Launer's method. Among these, it is relevant to note that those defined as stable stories often show some evolution, though it may be slight (nine expressions [25.7\%] from eight caregivers).

Finally, 46 expressions from the narrative plots of 44 HCPs could be classified according to Launer's method. To a lesser extent, these were found in stories defined as stable (19.6\%; nine expressions from eight HCPs). In contrast to the narratives collected from patients and caregivers, it is worth noting that more than half of all narratives collected from HCPs were stories in progression (56.5\%; 26 expressions from 25 HCPs). In these cases, the most common expression was "vaccine" or "vaccines" $(7,15.2 \%)$. A few narratives were identified as regressive stories $(23.9 \%$; 11 expressions from 11 people) (Figure 2).

\section{Classification by Kleinman}

According to Kleinman's classification, most narratives from participants with COPD were illness-centered (102 expressions from a total of 53 COPD patients) (Figure 2). Specifically, the number of recorded words indicating illness-centered narration was 84 ; these were mostly terms used to describe the "body" (82.3\%) such as "stiff" (17, $16.6 \%)$, "weak" $(11,10.8 \%)$, or "tired" $(8,7.8 \%)$. Other common terms were "fear" $(6,5.9 \%)$, specifically the fear of "dying" $(6,5.9 \%)$, and "dread" $(3,2.9 \%)$. Other images depicted an "anxious body" $(2,2 \%)$ or a "cold body" $(5$, $4.9 \%$ ). There were also 10 story expressions that were categorized as disease-centered (9.8\%, seven participants).

Nearly all $(90.9 \%)$ of the 22 narratives collected from caregivers and/or family members of people with COPD were characterized, according to Kleinman's classification, as illness-centered, whereas only a few stories $(9.09 \%)$ were considered disease-centered, ie, characterized by technical and specific descriptions of the activities performed by their loved one during the first lockdown or descriptions of specialist visits.

Forty-eight expressions from 28 HCPs were classifiable according to Kleinman's classification. Of these, most were considered disease-centered $(85.4 \% ; 41$ expressions from 24 HCPs), while the remainder were considered illness-centered (14.6\%; seven expressions from four HCPs). In the disease-centered narratives, the most commonly used term was "work" (7, 14.6\%), followed by "Covid" (6, 12.5\%); whereas in illness-centered narratives, the most used terms were "places" (3, 6.2\%), "anxiety"/ "anxious" (3, 6.2\%), "clinic" (1, 2.08\%), and "distress" $(1,2.08 \%$ ) (Figure 2). Neither COPD patients nor caregivers nor HCPs produced sickness-centered narratives, highlighting how social distancing can significantly diminish the cultural and social significance of a disease.

\section{COPD Metaphors}

Fifty-seven metaphors for COPD were used by 57 people with COPD. The most frequently used metaphor was "monster" (29, 50.9\%), followed by "friend" (8, $14.03 \%)$, "companion" (7, 12.3\%), and "bigger" or "great" $(5,8.8 \%)$, often used as adjectives. Similarly, 17 metaphors were used by 17 caregivers to represent their loved ones' COPD. Of these, the most common were "monster" $(3,17.6 \%)$ and "friend" $(2,11.8 \%)$.

Twenty-eight metaphors representing COPD were used by HCPs. Among these, "hungry/greedy monster" was used most frequently $(5,17.8 \%)$, followed by "companion" (4, 14.3\%) and "disease" (4, 14.3\%). "Disease" was referred to in combination with "breath" or "lungs" in three cases each $(10.71 \%)$ and with "death," "plan," or "point" in two cases each (7.1\%).

\section{COVID-19 Metaphors}

Sixty-two metaphors were used by 61 people with COPD to represent COVID-19. The most frequently used metaphor was "monster" $(29,46.7 \%)$, followed by "friend" ( 8 , $12.9 \%)$, "companion" $(7,11.3 \%)$, "murderer" and "bigger" or "great" $(5,8.06 \%)$, which were often used to describe COVID-19 in comparison with COPD.

Nineteen metaphors for COVID-19 were used by caregivers. "Monster" was the most frequently used metaphor, appearing in the narratives of six participants $(31.6 \%)$, 
followed by "invisible" $(5,26.3 \%)$, often associated with either "monster" or "enemy" $(3,15.8 \%)$. A couple of times it was described as an "insect" (10.5\%). Verbs such as "eat" (in connection with "breath" or "lungs") and adjectives such as "evil" were also used (10.5\%).

There were also 29 metaphors for COVID-19 used by HCPs, most commonly "monster" (7, 24.1\%), "ghost" (2, 6. 9\%), "enemy" (2, 6.9\%), and "leech" (2, 6.9\%). Compellingly, this "monster" was often referred to as one who "eats men" or "devours souls."

\section{The Experience of Writing}

Participants with COPD reported experiencing relief and peace of mind as a result of the experience of storytelling. Similar positive emotional outcomes were also reported by 18 caregivers. Of these, most said that writing gave them relief and pleasure. This is evident from the frequent use of the terms "better" $(4,22.2 \%)$, "serene" $(2,11.1 \%)$, and "venting" (2, 11.1\%). Among HCPs, nine participants (55.6\%) reported that the storytelling experience made them feel "better," while others mentioned feeling "relieved" $(2,22.2 \%)$ or "lighter" $(2,22.2 \%)$.

\section{Psychological Factors}

\section{Emotions}

A total of 240 expressions that referred to specific emotions were expressed by 71 participants with COPD regarding different moments in the year 2020. Among caregivers or family members of people with COPD, in contrast, only 50 expressions of emotions were expressed by 42 people, while 100 expressions were expressed by 38 HCPs (Figure 3).

The emotions most frequently reported by patients and caregivers were apprehension, terror, and fear (reported by about $25 \%$ of participants and $32 \%$ of caregivers), followed by pensiveness and vigilance (reported by $16.6 \%$ of caregivers). In particular, $58.22 \%$ of the emotions expressed by COPD patients in describing the first lockdown were terror, fear, and apprehension; in their descriptions of the reopening, these emotions accounted for only $35.44 \%$ of all emotional expressions. As for caregivers, $100 \%$ referred to terror, fear, and apprehension at lockdown, while only $45.83 \%$ referred to these emotions at the reopening. Terror, fear, and apprehension accounted for $42 \%$ of the emotional expressions by professionals describing their lockdown experiences (Figure 4).

\section{Social Factors}

\section{Caregiving}

The participating COPD patients sought and received 126 referrals to support during the health emergency, representing another coping strategy. Specifically, 77 referrals to support were identified during the first lockdown $(43.6 \%, 55$ participants) and 49 during the reopening period (38.9\%, 43 participants). The theme of receiving care from others was identified in 34 expressions by 31 caregivers. These included 18 expressions of receiving care from others in the first lockdown period (52.9\%; 17 participants) and 16 expressions of receiving care from others during the reopening period (47\%; 14 participants). Twenty-eight HCPs used 58 expressions to mention support received and/or perceived during the lockdown (56.9\%, 33 expressions; 28 participants) and reopening (43.1\%, 25 expressions; 25 participants). Importantly, participants identified four different ways to support and be supported: being present physically and mentally; being present physically, but not mentally; being present mentally, but not physically; and, finally, as shown in Figure 5, being absent both physically and mentally.

\section{Descriptions of the Home}

The home was described by 52 participants with COPD in 67 expressions. The most frequent statement about the home was that it had become a place where people were "forbidden to leave" $(49,73.1 \%)$ or that it was "impossible to leave" $(7,10.4 \%)$. Also notable were expressions about the home being "clean" $(6,8.9 \%)$ or "messy" $(2,2.9 \%)$, while there were five expressions about an "empty" home $(7.5 \%)$.

There were also 35 expressions on the topic of home by 19 caregivers. The following are the terms most frequently used by caregivers to describe the home: "going out" $(12,34.3 \%)$, "always" $(9,25.7 \%)$, and "place" (7, $20 \%)$, along with "cold" (4, 11.4\%), "clean" (3, 8.6\%), "messy" (2, 5.7\%), "hugs" (2, 5.7\%) and "prison" $(2,5.7 \%)$.

There were also 62 references to the home by 31 HCPs. Of these, 30 (48.4\%) were about the first lockdown period and $32(51.6 \%)$ were about the reopening period. During the first lockdown period, the home was predominantly described by HCPs with the term "none" (5, $8.06 \%)$. The home was also described as full of "anxiety" $(3,4.8 \%)$ or of "order" $(3,4.8 \%)$. For some, the home was where one could find one's "family" $(2,3.2 \%)$ or be "together" $(3,4.8 \%)$, which was a relevant coping and support factor. 


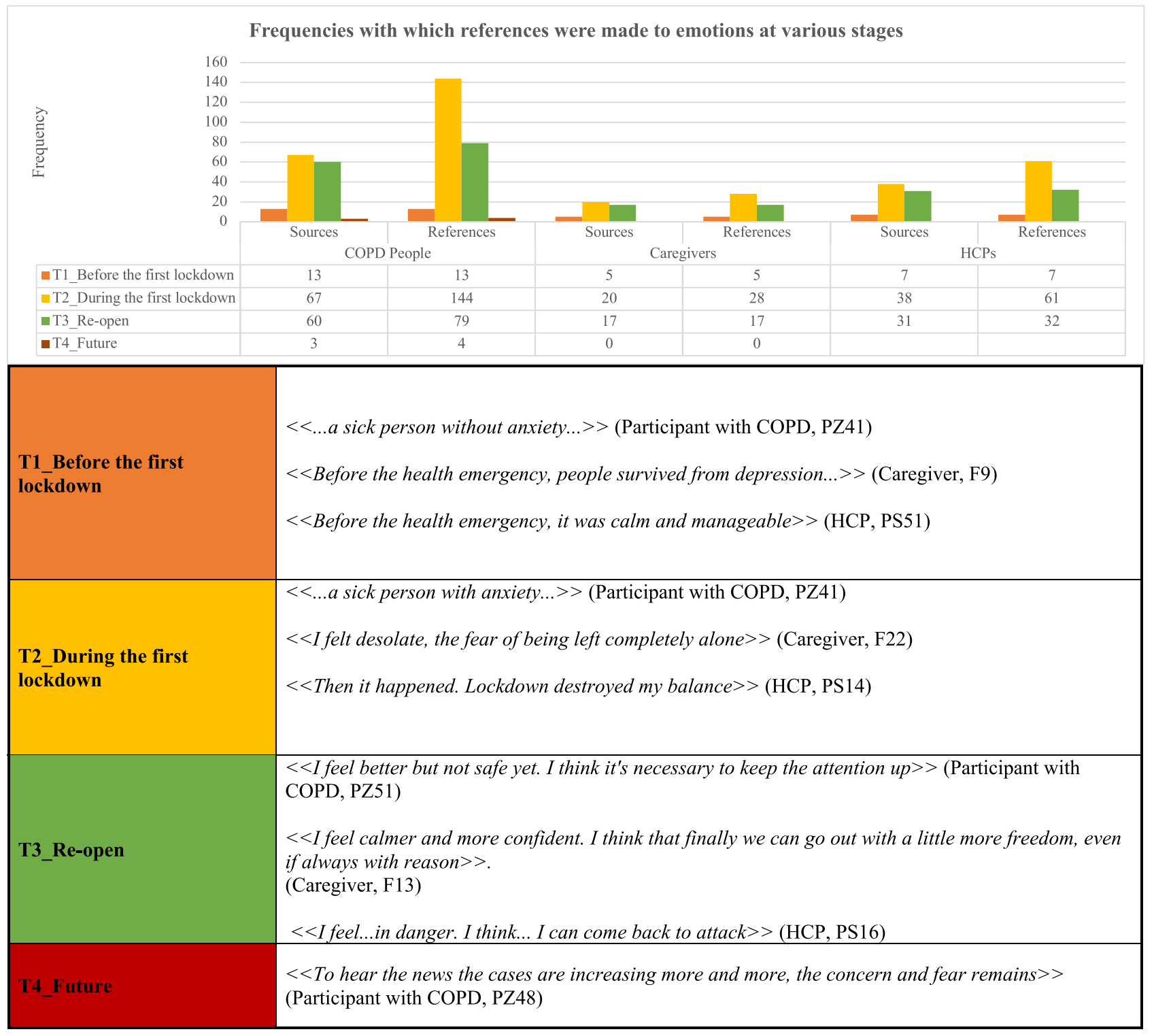

Figure 3 Frequencies with which particular emotions were expressed at various stages.

\section{Work}

Twenty-one references to work were found in the patient narratives (by 19 COPD patients). Of these, 14 referred to the first lockdown period $(73.7 \%$; 11 participants) while seven referred to the reopening period $(36.8 \%$; seven participants). During the first lockdown period, one of the terms most frequently used in relation to the verb "work" $(13,61.9 \%)$ was "impossible" $(5,23.8 \%)$. During the reopening period, in contrast, the terms most frequently used in connection with "work" were "difficult" $(2,9.5 \%)$ or "possible" (2, 9.5\%).

From 27 caregivers and/or family members of COPD patients, 29 expressions of employment emerged. Of these,
14 referred to the first lockdown period $(48.3 \%$; 14 persons), while the remaining 15 referred to the reopening period $(51.7 \%$; 13 persons). Regarding the first lockdown period, the terms most frequently used to describe work were "work" $(15,51.7 \%)$ or the combination of "work" with "impossible" $(3,10.3 \%)$ or "smart working," ie working from home or telecommuting $(3,10.3 \%)$. Adjectives such as "strenuous" $(2,7.4 \%)$, "challenging" $(2,7.4 \%)$, "attention"/“attentions" (1, 3.4\%), and "concentration" (1, $3.4 \%$ ) were also used by caregivers.

The HCPs used 146 expressions to refer to work; in these, the most common term was "places," often described as "chaotic" or "confusing" $(7,4.8 \%)$ or linked 


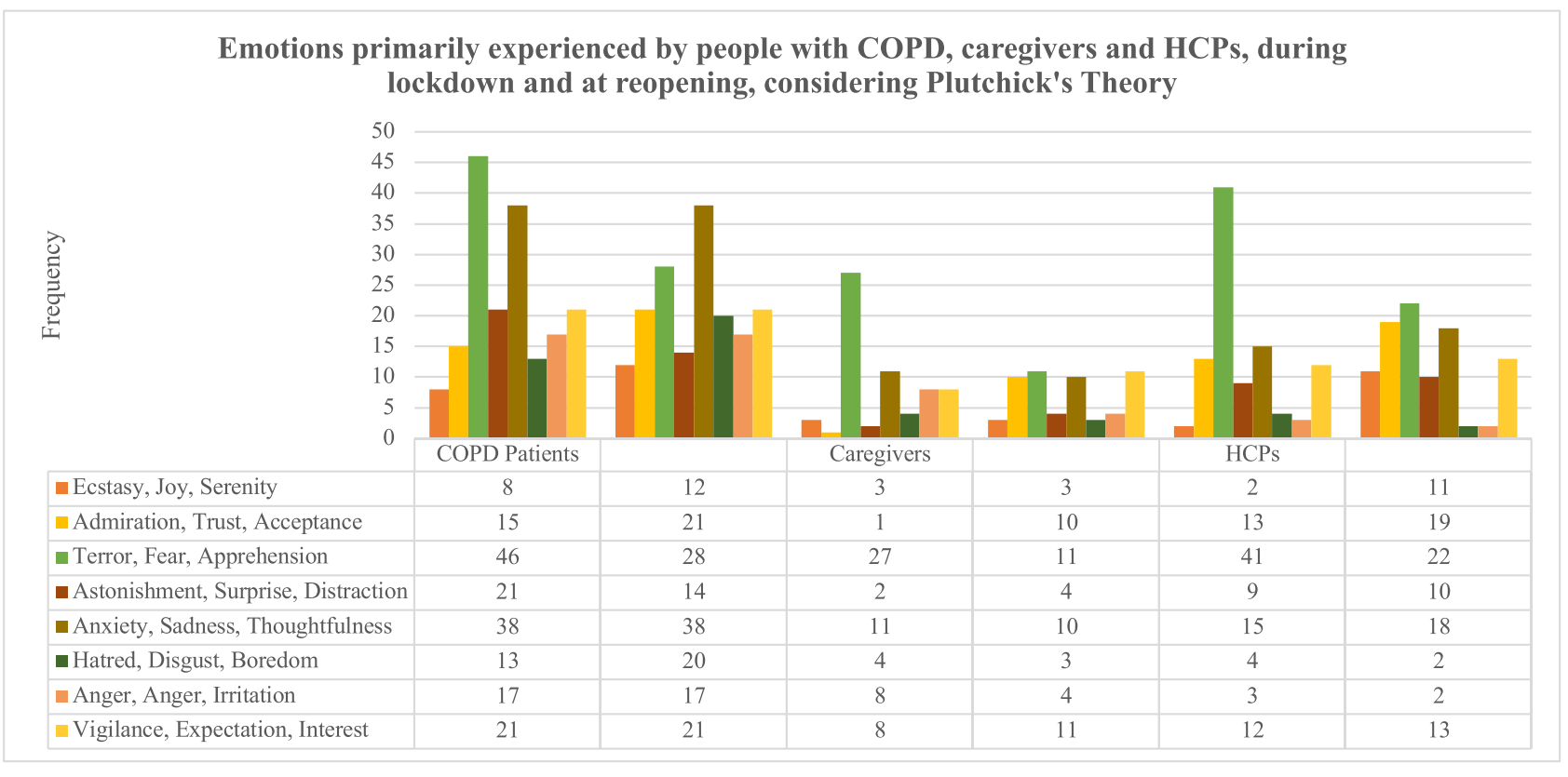

Figure 4 Emotions primarily experienced by people with COPD, caregivers, and HCPs during the lockdown and at the reopening, defined according to Plutchik's theory.

with "war"/"being at war" $(8,5.5 \%)$ or in the "trenches" $(3,2.05 \%)$.

\section{Coping Strategies Emerging from Narratives}

Globally, narrative plots indicated that coping strategies were being used by 42 COPD patients (45.2\%). Twentythree expressions of positive, proactive coping were expressed by 19 people with COPD (Table 2). There were also 36 expressions describing coping strategies used by a total of 19 family members and/or caregivers of people with COPD. The main strategy used was positive thoughts, primarily directed at loved ones and toward possible treatments.

\section{Discussion}

This cross-sectional observational study of NM aimed to explore how the COVID-19 pandemic impacted the quality of care, quality of life, psychological factors and social factors in people with COPD, their caregivers and families, and HCPs. Although a few studies have investigated the quality of care in COPD, ${ }^{20-22}$ no prior studies have explored it during pandemic times in Italy. Quantitative questionnaires and narratives of lived experiences during the pandemic were collected from 146 people, including 79 COPD patients, 24 caregivers, and 43 HCPs. Considering the total of 186 HCPs who were invited to participate, the participation rate was about $22 \%$, which was higher than expected. It is worth noting that, among participants with COPD, who tend to be older, $49.3 \%$ responded online, demonstrating that the COVID19 pandemic has convinced many of those who were least likely to use the new digital media to embrace it; nevertheless, $50.7 \%$ percent of people with COPD said they were insufficiently confident with new technologies or did not have a computer or smartphone, and opted for the telephone interview. We encouraged online participation but also permitted telephone interviews administered by qualified personnel to ensure that each protagonist's input on the care process was valued. The mosaic of narratives collected here from different points of view, including patients with COPD, ${ }^{23}$ caretakers, ${ }^{24}$ GPs, pulmonologists, and other $\mathrm{HCPs}^{25}$ working in respiratory therapy, represents a plurality of voices and tools that we can use to combat this highly destabilizing situation as it plays out over the long term.

It is well known that patients with COPD are prone to viral exacerbations, and evidence from epidemiologic studies suggests that patients with COPD are slightly more susceptible to SARS-CoV-2 infection, ${ }^{26,27}$ although the increased risk is higher for heart patients and diabetics. Of particular concern; however, is the finding that, once a person with COPD becomes infected with COVID-19, their prognosis worsens and their likelihood of needing mechanical ventilation and of mortality increases. ${ }^{28}$ Consequently, contrary to other studies that have reported a low impact of the lockdown on COPD patients, ${ }^{29}$ the 


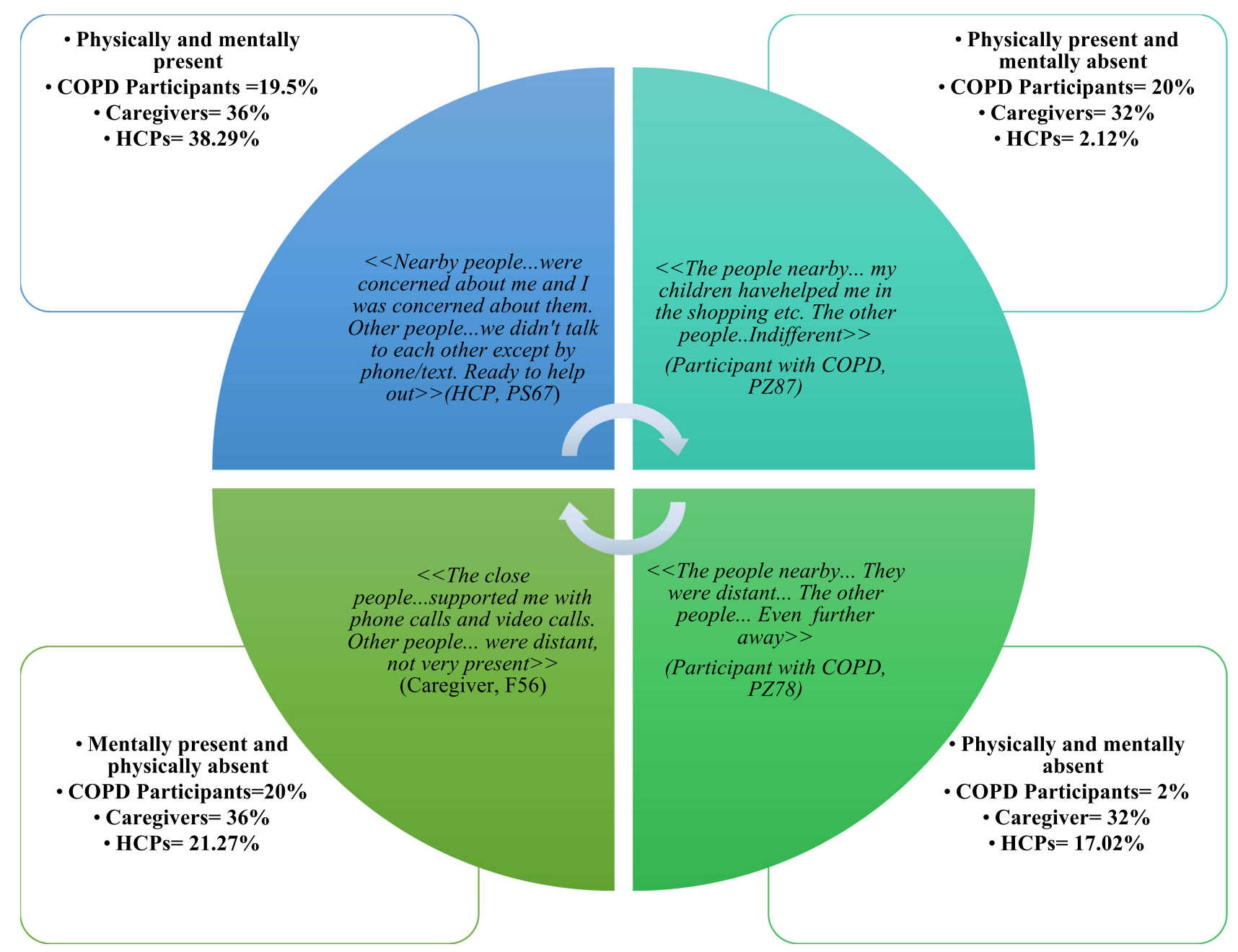

Figure 5 Matrix of support experienced during the pandemic and the percentages of expressions of each kind of support.

present study detected increased apprehension. In this scenario, as seen in the available literature about both the general population and those with other chronic diseases, the health emergency has forced patients and their families to face difficult changes and to radically modify their daily habits, finding themselves living solely at home, sometimes very isolated and without the possibility of resorting to the usual social-assistance aids. In individuals with disabilities and chronic conditions, Umucu and Lee found that perceived stress related to COVID-19 was positively associated with coping strategies including selfdistraction, denial, substance use, behavioral disengagement, venting, planning, religion, and self-blame. ${ }^{30}$ Consistent with the literature on emotional reactions during previous pandemic periods, higher risk perception was associated with higher levels of overall negative emotion and individual negative emotions. ${ }^{31-33}$ Indeed, in the present pandemic, which has disrupted all the usual routines, stress exposure is high, and represents a new source of stress never experienced in any of the participants' own lifetimes. Therefore, it is understandable that they are experiencing unpleasant and complex emotional states. This is a possible explanation for the high proportions of stable and regressive stories collected and for the distribution of emotions as defined using the Plutchik wheel. ${ }^{34,35}$ Although most COPD respondents did not contract the virus, they left testimony of their significant mental vulnerability, worthy of concern and consideration for the organization and optimization of healthcare services. In fact, from the 146 narratives collected between July and December 2020, the dimension of horror emerged, which may be far more serious than the war metaphors typically used by the media and in other studies. ${ }^{36}$ For $60 \%$ of patients and $100 \%$ of caregivers, fear was the most frequently cited emotion, due to the possible repercussions of COVID-19 on their respiratory capacity, which was 
Table 2 Specific Coping Strategies Adopted During Pandemic Times by COPD People, Caregivers and Health Care Professionals

\begin{tabular}{|c|c|c|}
\hline \multirow[t]{2}{*}{$\begin{array}{l}\text { Activities considered } \\
\text { enjoyable or hobbies }\end{array}$} & $\begin{array}{l}\text { COPD People } \\
(5,21.7 \%) \\
\text { Caregivers }\end{array}$ & $\begin{array}{l}\ll \ldots \text { I feel good by myself because I always find something to do, read, inform myself, play with } \\
\text { the pc or learn new things of every kind } \gg \text { (Participant with COPD, PZ03) } \\
\text { - }\end{array}$ \\
\hline & HCPs & - \\
\hline \multirow[t]{3}{*}{$\begin{array}{l}\text { The hope of finding loved } \\
\text { ones }\end{array}$} & $\begin{array}{l}\text { COPD People } \\
(3,13.04 \%)\end{array}$ & $\begin{array}{l}\ll \ldots \text { I had to stay calm and reason because I have three grandchildren and an only daughter } \\
\text { living in the USA and I want to see them again ... \» (Participant with COPD, PZ5I) }\end{array}$ \\
\hline & Caregivers & - \\
\hline & $\mathrm{HCPs}$ & - \\
\hline \multirow[t]{3}{*}{ Positive thinking or humor } & $\begin{array}{l}\text { COPD People } \\
(2,8.7 \%)\end{array}$ & $\begin{array}{l}\ll \ldots \text { That I am fortunate to be able to live with family and be so well cared for ... } \gg \\
\text { (Participant with COPD, PZ52) }\end{array}$ \\
\hline & $\begin{array}{l}\text { Caregivers }(24, \\
58.3 \%)\end{array}$ & $\begin{array}{l}\text { « For tomorrow I guess ....I want to be positive and think that this pandemic can go away the } \\
\text { way it came» (Caregiver, F43) }\end{array}$ \\
\hline & $\begin{array}{l}\text { HCPs }(13, \\
27.7 \%)\end{array}$ & $\begin{array}{l}\ll \text { Softly, more and more consistently the fact that COVID had come to my neck of the woods } \\
\text { had taken hold. Like the inscriptions on cigarette packets ... cigarette smoke can give you cancer. } \\
\text { The smoker thinks that it can come to someone else, but never to him. But then some friend or } \\
\text { family member gets seriously ill and changes their mind. Suddenly with the fact that you could be } \\
\text { identified as a panic doctor, because in February you were guilty of making the nurses wear } \\
\text { masks as a precaution, it became a matter of conditional admissions ....We suddenly became } \\
\text { "ghostbusters" ... all wearing masks, goggles, gloves, disposable suits, even to carry the car!!!!! } \\
\text { Personalized guidelines, which changed almost weekly, ... equally changing according to what } \\
\text { they divulged virologists interviewed daily by various television programs .......... } \text { (HCP, } \\
\text { PS29) }\end{array}$ \\
\hline \multirow[t]{3}{*}{$\begin{array}{l}\text { Protection of self and of } \\
\text { the other }\end{array}$} & $\begin{array}{l}\text { COPD People } \\
(6,2 \%)\end{array}$ & $\ll I$ honestly stayed at home» (Participant with COPD, PZ05) \\
\hline & $\begin{array}{l}\text { Caregivers }(10, \\
33.04 \%)\end{array}$ & $\begin{array}{l}\ll I \text { think that even if the disease is subtle, staying at home and respecting the rules and avoiding } \\
\text { crowded schedules for shopping or weekends I do not say that we live it differently but in } \\
\text { a serene and quiet way even if we continue to hear these things on TV but sometimes, we change } \\
\text { the channel, we prefer to see futile things rather than the news, we avoid so we are better, so } \\
\text { much so if we respect the rules nothing serious should happen》 (Caregiver, F55) }\end{array}$ \\
\hline & $\operatorname{HCPs}(6,12.8 \%)$ & $\begin{array}{l}\ll \ldots \text { I felt that the health of my family members was very much at risk and I kept them at } \\
\text { a distance ... 》 (HCP, PS76) }\end{array}$ \\
\hline \multirow{3}{*}{$\begin{array}{l}\text { Organization and problem } \\
\text { solving }\end{array}$} & COPD People & - \\
\hline & $\begin{array}{l}\text { Caregivers }(1, \\
4 \%)\end{array}$ & $\begin{array}{l}\text { 《 Getting out of the house was just me taking care of the expenses and going to work» } \\
\text { (Caregiver, F55) }\end{array}$ \\
\hline & $\begin{array}{l}\text { HCPs }(14, \\
29.8 \%)\end{array}$ & $\begin{array}{l}\text { 《The virus and lockdown have arrived. At this stage, work patterns were disrupted. However, } \\
\text { I have tried to maintain that relationship of proximity with the patients. Through phone calls, } \\
\text { messages, video calls. I always left the office open at the usual times (albeit with security rules) } \\
\text { and visited suspects in the office (at separate times) or at home. always leaving the study open } \\
\text { with the usual timetables (also with safety rules), visiting in study (in separate timetables) or to } \\
\text { house the suspects covid, leaving availability to be contacted also to the Saturday and to the } \\
\text { Sunday》 (HCP, } 78)\end{array}$ \\
\hline
\end{tabular}

(Continued) 
Table 2 (Continued).

\begin{tabular}{|c|c|c|}
\hline \multirow[t]{3}{*}{ Self-care } & $\begin{array}{l}\text { COPD People } \\
(4,17.4 \%)\end{array}$ & $\begin{array}{l}\text { «I kept myself always trained on the treadmill, every day including Saturday and Sunday, I never } \\
\text { gave up maybe that's why all in all I managed to overcome him ... } \\
\text { PZ77) }\end{array}$ \\
\hline & Caregivers & - \\
\hline & $\mathrm{HCPs}$ & - \\
\hline \multirow[t]{3}{*}{ Adjusting expectations } & $\begin{array}{l}\text { COPD People } \\
(2,8.4 \%)\end{array}$ & $\begin{array}{l}\ll \ldots \text { to continue to be quite well in the hope that more and more effective medications against } \\
\text { COPD will be found ....» (Participant with COPD, PZ56) }\end{array}$ \\
\hline & $\begin{array}{l}\text { Caregivers }(1, \\
4 \%)\end{array}$ & $\begin{array}{l}\ll I \text { think ... that we must take advantage of this moment so that my wife can regain her breath } \\
\text { in the true sense of the word } \ldots . \gg \text { (Caregiver, F89) }\end{array}$ \\
\hline & $\mathrm{HCPs}$ & - \\
\hline \multirow[t]{3}{*}{ Spirituality } & $\begin{array}{l}\text { COPD People } \\
(1,4.3 \%)\end{array}$ & $\ll I$ also began to pray ... 》 (Participant with COPD, PZI5) \\
\hline & Caregivers & - \\
\hline & $\mathrm{HCPs}$ & - \\
\hline
\end{tabular}

already strained by the underlying chronic disease. Dread and apprehension were also among the most frequent emotions expressed by $42 \%$ of healthcare professionals during the first lockdown, mainly due to the fear of infecting loved ones. The home was not evoked as a place of protection, but as a "reservoir of anxiety," a cold place without hugs, where disinfection procedures were the new routine. These narratives allow us to understand how the fear of contracting COVID-19, a second lung disease, was lived in those who already had COPD. Moreover, although the sample was not particularly large, the emotions detected were so strongly clustered on fear, apprehension, and anxiety that they may be generalizable to others living through the same event.

The narratives are typically very short, contingent, and telegraphic, as if the participants had difficulty expressing their experience, as if the stories were not yet ready to be told. The use of metaphorical monstrous images to represent COVID-19 and COPD express the fear and terror these people experienced, as do their descriptions of their own homes as no longer the safe places they had been but now places of contagion that induced fear. Apprehension, pensiveness, and vigilance, together with fear, were among the emotions most frequently reported by our sample of patients and caregivers: in this regard, we can believe that vulnerability does not mean inadequacy, that learning to ask for help is an act of humility and courage, and that openness to change allows us not to get stuck living a disease-oriented life. ${ }^{37,38}$ Interestingly, COPD is almost always described as a limitation, but it was perceived in 2020 as less dangerous than COVID-19, which triggered more fear. Therefore, while the former represents a challenge that returns cyclically, but seems more manageable, the latter seems insurmountable, uncontrollable. As each narrative is a mirror of a person's internal state, we measured the movement of the narratives using both Launer's and Kleinman's classifications. It is therefore relevant to note that HCPs narrated their stories in a more disease-centered manner than caregivers and patients did. In contrast, there were no sickness-centered stories among any the narratives we collected, likely due to the abrupt halt of our participants' social lives, where their macrosocial limitations (economic, political, institutional) were most evident.

Patients and caregivers complained in 2020 that, in many areas of Italy, health services that were considered non-essential (eg outpatient rehab/therapy services, medical check-ups, and other allied health services such as dietetics, counseling, social work, psychology, and podiatry) were significantly reduced due to the pandemic, to limit the spread of contagion; this includes services dedicated to COPD monitoring. On the other hand, fear of contagion led individuals to stay away from hospital settings unless there was an emergency. Meanwhile, all the other barriers to COPD care that existed before COVID-19 continued to exist. For example, waiting time in hospitals 
was extended, communication and relationships with healthcare providers were much less efficient as HCPs' workload became concentrated on COVID-19 and other urgent diseases, and stress levels increased, which can result in lower adherence to self-management measures. In this sense, telemedicine has been a source of comfort to those who have used it, confirming previous research and available data from other countries. ${ }^{39,40}$ Nevertheless, the discrepancy between the number of HCPs who reported having implemented remote services and the number of patients who reported having used them should prompt much thought about steps to increase the use of this resource. ${ }^{40,41}$ An effective COPD healthcare service system should be continuous, multidimensional, multidisciplinary, and multilevel, with care paths centered on the patient: this macro-process should also contemplate the implementation of telemedicine, connecting patients and caregivers to GPs, pulmonologists, and specialists.

Despite the innovative power and the relevant results of this study, some limitations should be considered to improve future studies. The present findings should be cautiously generalized, especially regarding the sample of caregivers, because our caregiver participants were mainly well-educated women. This study's requirement of written self-reflection might be associated with the high levels of education and literacy, as it could have appeared as a barrier to participation for persons with lower education levels. Most participants in both the online and telephone interviews reported being satisfied or very satisfied with their ability and opportunity to express their true feelings during the interview. Regarding the comparability of data that emerged from the online and phone interviews, $100 \%$ of the online and phone interviews provided insight into the experiences and quality of care during the period related to the health emergency. Although they were insightful, online responses tended to be shorter, or even, at times, underdeveloped. Similarly, our sample of HCPs consisted mostly of physiotherapists. Moreover, lacking a larger sample, it is not possible to assess whether there were statistically significant differences between subgroups divided by geographic area, socioeconomic status, or age. Another limitation of the study is that, in assessing HCPs' experiences with telemedicine, it obtained only a broad overview in aggregate form. Subsequent studies are therefore necessary to deepen our knowledge of the experiences of HCPs in different professional fields. Additionally, further research is needed to understand the barriers to and facilitators of the use of telemedicine by
COPD patients to determine how these technologies can be most effectively integrated into HCPs' workflows and clinical decision-making practices.

\section{Conclusion}

This study represented the first Italian project to simultaneously address and integrate three perspectives on COPD (patients, caregivers, and HCPs), giving voice to the COPD experience during pandemic times. The picture of profound psychological distress that has emerged reveals the need to integrate and increase the network of psychological support as well as to reduce excessive risk perception and regulate emotions through interventions offered to COPD patients, who are already in a fragile state, when they become exposed to conditions inducing pandemic fatigue. These findings can be taken as a foundation for further research on and dissemination of such interventions. In particular, NM allowed us to reflect on the uniqueness of the COPD patient pandemic experience, stressing the vulnerability lived by both patients and caregivers and evidencing the importance of empowering multilevel services that integrate psychological support programs and telemedicine.

\section{Abbreviations}

COPD, chronic obstructive pulmonary disease; GPs, general practitioners; HCPs, health care professionals; NM, narrative medicine; QoL, quality of life; PPE, personal protective equipment.

\section{Data Sharing Statement}

All datasets used and analyzed during the current research are available in Italian from the corresponding author upon reasonable request.

\section{Ethics Approval and Consent to Participate}

The project was conducted in accordance with the Declaration of Helsinki and was approved by the Institutional Review Board of the "IRCCS Fondazione Don Carlo Gnocchi" del Comitato Etico IRCCS Regione Lombardia (09/12/2020). Participants provided online written informed consent after being informed on the project's aims and confidential data handling procedures, according to Italian Law $196 / 2003$ on Privacy and Safeguarding of Sensitive Data and the GDPR of the European Union 2016/679. 


\section{Acknowledgments}

The authors wish to thank Chiesi S.p.A. for its contribution to this project.

The authors would like to thank Enago (www.enago.

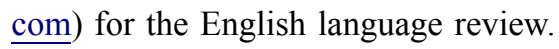

\section{Author Contributions}

MGM, AP, and LC were involved in the conceptualization of the project. EV and MGM contributed to data analysis, and MGM and EV contributed to project investigation. EV and the Cooperative Group of COPD and Covid-19 Narrative Medicine enrolled people with COPD. EV and MGM were involved in methodology, project administration, and the analysis of the narratives; the Cooperative Group of COPD and Covid-19 Narrative Medicine was involved in data validation. EV and MGM contributed to the writing; all authors contributed to reporting visualization. All authors made substantial contributions to conception and design, acquisition of data, or analysis and interpretation of data; took part in drafting the article or revising it critically for important intellectual content; agreed to submit to the current journal; gave final approval of the version to be published; and agree to be accountable for all aspects of the work.

\section{Funding}

This work was supported by Chiesi S.p.A.

\section{Disclosure}

Dr Eleonora Volpato reports support for this study from Chiesi Farmaceutici S.p.A. Dr Alessio Piraino and Dr Luca Cavalieri are employers of Chiesti Italia S.p.A. The authors report no other conflicts of interest in this work.

\section{References}

1. Mathers CD, Loncar D, Samet J. Projections of global mortality and burden of disease from 2002 to 2030. PLoS Med. 2006;3(11):e442. doi:10.1371/journal.pmed.0030442

2. Lu R, Zhao X, Li J, et al. Genomic characterization and epidemiology of 2019 novel coronavirus: implications for virus origins and receptor binding. Lancet. 2020;395(10224):565-574. doi:10.1016/S01406736(20)30251-8

3. Zhang L, Shen FM, Chen F, Lin Z. Origin and evolution of the 2019 novel coronavirus. Clin Infect Dis. 2020;71(15):882-883. doi:10.1093/ $\mathrm{cid} / \mathrm{ciaa} 112$

4. Garg S, Kim L, Whitaker M, et al. Hospitalization rates and characteristics of patients hospitalized with laboratory-confirmed coronavirus disease 2019-COVID-NET, 14 States, March 1-30, 2020. MMWR Morb Mortal Wkly Rep. 2020;69(15):458-464. doi:10.15585/mmwr. $\mathrm{mm} 6915 \mathrm{e} 3$

5. Yohannes AM, Baldwin RC, Connolly MJ. Mood disorders in elderly patients with chronic obstructive pulmonary disease. Rev Clin Gerontol. 2000;10(2):193-202. doi:10.1017/S0959259800002100
6. Yohannes AM. COPD patients in a COVID-19 society: depression and anxiety. Expert Rev Respir Med. 2021;15(1):5-7. doi:10.1080/ 17476348.2020.1787835

7. Holmes EA, O'Connor RC, Perry VH, et al. Multidisciplinary research priorities for the COVID-19 pandemic: a call for action for mental health science. Lancet Psychiatry. 2020;7(6):547-560. doi:10.1016/S2215-0366(20)30168-1

8. Charon R. Narrative and medicine. $N$ Engl J Med. 2004;350 (9):862-864. doi:10.1056/nejmp038249

9. Marini MG. Languages of Care in Narrative Medicine; 2019. doi:10.1007/978-3-319-94727-3

10. Greenhalgh T, Jackson C, Shaw S, Janamian T. Achieving research impact through co-creation in community-based health services: literature review and case study. Milbank Q. 2016;94(2):392-429. doi:10.1111/1468-0009.12197

11. Charon R. The patient-physician relationship. Narrative medicine: a model for empathy, reflection, profession, and trust. JAMA. 2001;286(15):1897-1902.

12. Istituto Superiore di Sanità, Centro Nazionale Malattie Rare C di C. 2015. Linee di indirizzo per l'applicazione della medicina narrativa in ambito clinico-assistenziale, per le malattie rare e cronicodegenerative. IL SOLE 24 ORE SANITA. Avialable from: http:// www.iss.it $/ \mathrm{cnmr} /$ index.php?lang=1\&id=2562\&tipo=82.

13. Peeters B, Marini MG. Narrative Medicine Across Languages and Cultures: Using Minimal English for Increased Comparability of Patients' Narratives. Minimal English for a Global World; 2018; doi:10.1007/978-3-319-62512-6_11

14. GOLD Report. Global initiative for chronic obstructive lung disease 2020 Report. Glob Initiat Chronic Obstr Lung Dis. 2020.

15. Plutchik R. The Emotions. University Press of America; 1991.

16. Kleinman A. The illness narratives: suffering, healing, and the human condition. Acad Med. 2017;92(10):1406. doi:10.1097/ ACM.0000000000001864

17. Launer J. New stories for old: narrative-based primary care in Great Britain. Fam Syst Heal. 2006;24(3):336-344. doi:10.1037/10917527.24.3.336

18. Weiten W, Lloyd MA. Psychology Applied to Modern Life. 9th ed. (Wadsworth Cengage Learning, ed.); 2008

19. Snyder CR. Coping: The Psychology of What Works. Oxford University Press; 1999.

20. Negewo NA, Gibson PG, McDonald VM. COPD and its comorbidities: impact, measurement and mechanisms. Respirology. 2015;20 (8):1160-1171. doi:10.1111/resp. 12642

21. O’Donnell DE, Milne KM, James MD, de Torres JP, Neder JA. Dyspnea in COPD: new mechanistic insights and management implications. $A d v$ Ther. 2020;37(1):41-60. doi:10.1007/s12325-019-01128-9

22. Gatti V, Banfi P, Centanni S, et al. Enlightening chronic obstructive pulmonary disease through patients' and caregivers' narratives. Int J Chron Obstruct Pulmon Dis. 2018;13:3095-3105. doi:10.2147/ COPD.S172214

23. Brighton LJ, Bristowe K, Bayly J, et al. Experiences of pulmonary rehabilitation in people living with chronic obstructive pulmonary disease and frailty. A qualitative interview dtudy. Ann Am Thorac Soc. 2020;17(10):1213-1221. doi:10.1513/AnnalsATS.201910$800 \mathrm{OC}$

24. Rapelli G, Lopez G, Donato S, et al. A Postcard From Italy: challenges and psychosocial resources of partners living with and without a chronic disease during COVID-19 epidemic. Front Psychol. 2020;11:567522. doi:10.3389/fpsyg.2020.567522

25. Trumello C, Bramanti SM, Ballarotto G, et al. Psychological adjustment of healthcare workers in Italy during the COVID-19 pandemic: differences in stress, anxiety, depression, burnout, secondary trauma, and compassion satisfaction between frontline and non-frontline professionals. Int J Environ Res Public Health. 2020;17(22):8358. doi:10.3390/ijerph17228358 
26. Olloquequi J. COVID-19 Susceptibility in chronic obstructive pulmonary disease. Eur J Clin Invest. 2020;50(10):e13382. doi:10.1111/ eci. 13382

27. Higham A, Mathioudakis A, Vestbo J, Singh D. COVID-19 and COPD: a narrative review of the basic science and clinical outcomes. Eur Respir Rev. 2020;29:158. doi:10.1183/ 16000617.0199-2020

28. Leung JM, Niikura M, Yang CWT, Sin DD. COVID-19 and COPD. Eur Respir J. 2020;56:2. doi:10.1183/13993003.02108-2020

29. Pleguezuelos E, Del Carmen A, Moreno E, et al. The experience of COPD patients in lockdown due to the COVID-19 pandemic. Int J COPD. 2020;15:2621-2627. doi:10.2147/COPD.S268421

30. Umucu E, Lee B. Examining the impact of COVID-19 on stress and coping strategies in individuals with disabilities and chronic conditions. Rehabil Psychol. 2020;65(3):193-198. doi:10.1037/ rep0000328

31. Prati G, Pietrantoni L, Zani B. A social-cognitive model of pandemic influenza H1N1 risk perception and recommended behaviors in Italy. Risk Anal. 2011;31(4):645-656. doi:10.1111/j.1539-6924.2010.0 1529.x

32. Yang JZ, Chu H. Who is afraid of the Ebola outbreak? The influence of discrete emotions on risk perception. J Risk Res. 2018;21 (7):834-853. doi:10.1080/13669877.2016.1247378

33. Han Q, Zheng B, Agostini M, et al. Associations of risk perception of COVID-19 with emotion and mental health during the pandemic. $J$ Affect Disord. 2021;284:247-255. doi:10.1016/j.jad.2021.01.049

34. Philip KEJ, Lonergan B, Cumella A, Farrington-Douglas J, Laffan M, Hopkinson NS. COVID-19 related concerns of people with long-term respiratory conditions: a qualitative study. $B M C$ Pulm Med. 2020;20(1):319. doi:10.1186/s12890-020-01363-9
35. McAuley H, Hadley K, Elneima O, et al. COPD in the time of COVID-19: an analysis of acute exacerbations and reported behavioural changes in patients with COPD. ERJ Open Res. 2021;7:1. doi: $10.1183 / 23120541.00718-2020$

36. Semino E. "Not soldiers but fire-fighters"-metaphors and Covid-19. Health Commun. 2021;36(1):50-58. doi:10.1080/10410236.20 20.1844989

37. Mousing CA, Sørensen D. Living with the risk of being infected: COPD patients' experiences during the coronavirus pandemic. J Clin Nurs. 2021;30(11-12):1719-1729. doi:10.1111/jocn.15727

38. Pedrozo-Pupo JC, Campo-Arias A. Depression, perceived stress related to COVID, post-traumatic stress, and insomnia among asthma and COPD patients during the COVID-19 pandemic. Chron Respir Dis. 2020;17:1479973120962800. doi:10.1177/1479973120962800

39. Boyce DM, Thomashow BM, Sullivan J, Tal-Singer R. New adopters of telemedicine during the coronavirus-19 pandemic in respondents to an online community survey: the case for access to remote management tools for individuals with chronic obstructive pulmonary disease. Chronic Obstr Pulm Dis. 2021;8(2):213-218. doi:10.15326/ JCOPDF.2020.0181

40. Wu F, Burt J, Chowdhury T, et al. Specialty COPD care during COVID-19: patient and clinician perspectives on remote delivery. BMJ Open Respir Res. 2021;8:1. doi:10.1136/bmjresp-2020-000817

41. Ding H, Fatehi F, Maiorana A, Bashi N, Hu W, Edwards I. Digital health for COPD care: the current state of play. J Thorac Dis. 2019;11(Suppl 17):S2210-S2220. doi:10.21037/jtd.2019.10.17

\section{Publish your work in this journal}

The International Journal of COPD is an international, peer-reviewed journal of therapeutics and pharmacology focusing on concise rapid reporting of clinical studies and reviews in COPD. Special focus is given to the pathophysiological processes underlying the disease, intervention programs, patient focused education, and self management protocols. This journal is indexed on PubMed Central, MedLine and CAS. The manuscript management system is completely online and includes a very quick and fair peer-review system, which is all easy to use. Visit http://www.dovepress.com/testimonials.php to read real quotes from published authors. 